\title{
Volume Fraction Effect for the Film Formation of PS/PVA Composites by Monitoring Photon Transmission Technique
}

\author{
Sibel Eken Korkut ${ }^{1 *}$ \\ 1*Yildiz Technical University, Faculty of Arts \& Sciences, Departmant of Chemistry, İstanbul, Turkey, (ORCID: 0000-0001-9637-5541), sibeleken@gmail.com
}

(First received 22 March 2021 and in final form 27 June 2021)

(DOI: 10.31590/ejosat.900841)

ATIF/REFERENCE: Eken Korkut, S. (2021). Volume Fraction Effect for the Film Formation of PS/PVA Composites by Monitoring Photon Transmission Technique. European Journal of Science and Technology, (25), 267-271.

\begin{abstract}
Film forming of the polystrene (PS) doped Poly Vinyl Alcohol (PVA) particles were studied by photon transmission (PT) technique. The films were prepared as a mixture of PS and PVA particles at different compositions ranging from 10 to $100 \mathrm{wt} \%$ for the optical measurements at room temperature the film formation process was monitored by measuring the transmitted light intensity $\left(\mathrm{I}_{\mathrm{tr}}\right)$ from the samples using PT. The film formation includes two stages: void closure and interdiffusion stages. Percolation model was employed to interpret the distribution of PS particles in PVA lattice. Percolation threshold, $\mathrm{R}_{\mathrm{c}}$, was found to be as 0.4 and the volume fraction of PVA as a power law with exponent 1.01 which is very close to the predicted value, 1.00 , by the percolation theory.
\end{abstract}

Keywords: PS, PVA, Mechanic, Photon Transmission, Activation Energies.

\section{PS/PVA Kompozitlerinin Film Oluşumuna Hacim Kesri Etkisinin Işıłk Geçirgenliği ile İzlenmesi}

Öz

Polistren (PS) katkılı Poli Vinil Alkol (PVA) dağılımının film oluşum süreci foton geçirgenliği (PT) teknikle incelenmiştir. Filmler, oda sıcaklığında optik ölçümler için ağırlıkça \%10 ile \%100 arasında değişen farklı bileşimlerde PS ve PVA dağılımının bir karışımı olarak hazırlandı. Film oluşum süreci, PT kullanılarak numunelerden geçen 1şık şiddeti $\left(\mathrm{I}_{\mathrm{tr}}\right)$ ölçülerek izlendi. Film oluşumunun iki aşamada gerçekleştiği gözlemlendi: boşluk kapanması ve difüzyon aşamaları. PVA kafesinde PS parçacıklarının dağılımını yorumlamak için süzme modeli kullanıldı. Süzme teorisine göre, perkolasyon eşiği $R_{c} 0,4$ ve PVA'nın hacim kesri için 1.01 tahmin edilen değer olan 1,00'e çok yakın bulunmuştur.

Anahtar Kelimeler: PS, PVA, Mekanik, Foton Taşınımı, Aktivasyon Enerjisi.

\footnotetext{
*Corresponding Author: xxxx@xxx.xx.xx
} 


\section{Introduction}

Latex film formation could be obtained by Theoretical and experimental efforts in literature,(Provder T., 1996). Film formation process of polymer latex can be explained by three steps: (i) water evaporation, deformation and the annealing process. In the annealing of hard latex system, deformation of particles first leads to void closure(Mackenzie \& Shuttleworth, 1949; Sperry, Snyder, Odowd, \& Lesko, 1994) and then diffusion across particle-particle boundaries start, i.e. the mechanical properties of hard latex films evolve during annealing. (iii) Coalescence of the deformed particles to form a homogeneous film(Mackenzie \& Shuttleworth, 1949) where macromolecules belonging to different particles mix by interdiffusion(Pekcan, 1997; Yoo, Sperling, Glinka, \& Klein, 1991).

For the last years, producing new materials by filling polymers with inorganic natural or synthetic compounds is gaining intension (Ray \& Okamoto, 2003).

(Hallensleben, 2000; Kelly, DeMerlis, Schoneker, \& Borzelleca, 2003). PVA has many advantages for industrial products such as adhesive, coatings, surfactant, films, packaging, biodegradable plastic backing sheet in hygiene products (Hallensleben, 2000), and biomedical applications(Jiang, Liu, \& Feng, 2011; Yang, Li, \& Nie, 2007).

Here, film formation of PS/PVA composite films. The reason of usage of Polystyrene (PS) is that easily processing, its solubility in many different types of solvents and its clarity which allows dispersion of PVA to be optically observed at the micron scale. After each annealing step of PS/PVA films having various compositions above $\mathrm{T}_{\mathrm{g}}$ of $\mathrm{PS}, \mathrm{I}_{\mathrm{tr}}$, was followed during the film formation. Activation energies were computed with respect to the change of $I_{t r}$. Percolation threshold, $R_{c}$, was found to be as 0.4 (40 wt\% PS).

\section{Material and Method}

\subsection{Materials}

PS latexes were prepared by polymerization process of styrene (99 \% pure from Alfa Asea) as a monomer, dimethacrylate (PolyFluorTM 511 from Polysciences, Inc.) and KPS (Potassium persulphate) was used as an initiator. KPS added after dissolved at $90^{\circ} \mathrm{C}$. Polyvinyl alcohol (PVA) (Boysan Co., Turkey) was purchased in white powder form. $0.01 \mathrm{gr} / \mathrm{ml}$ PVA was prepared as a stock.

\subsection{PS/PVA Composite Film Preparation}

Eight different films by mixing of PS and PVA. A drop cast methode was used for the preparation of the samples. Equal drops were put on a glass plates with the size of $0.5 \times 2.2 \mathrm{~cm}^{2}$ after drying of solution. PS volume in matrix as 10, 20, 40, 60, $80,90,100 \mathrm{wt} \%$. After drying (at room temperature), all samples were annealed starting from 100 to $270^{\circ} \mathrm{C}$.

\subsection{Optical Measurements}

UV Visible Spectrometer (BW\&TEK) was used as a for $\mathrm{I}_{\text {tr }}$ measurements at room conditions. Film positions should be perpendicular to the light as in Fig 1. SEM images of pure PS and $40 \%$ wt PS films In Fig2a and b, respectiveley
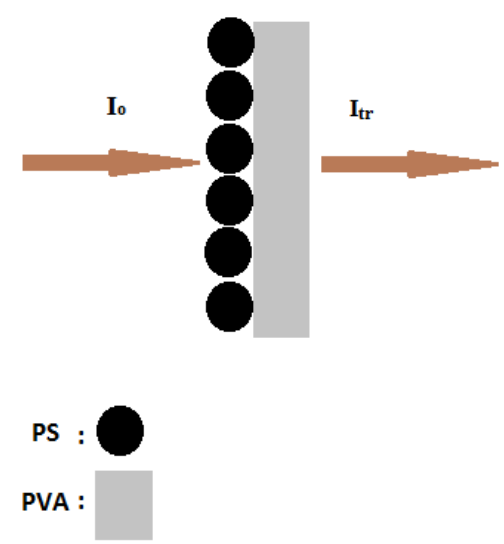

Figure 1. A cartoon figure of the film position to the light and the transmitted light.

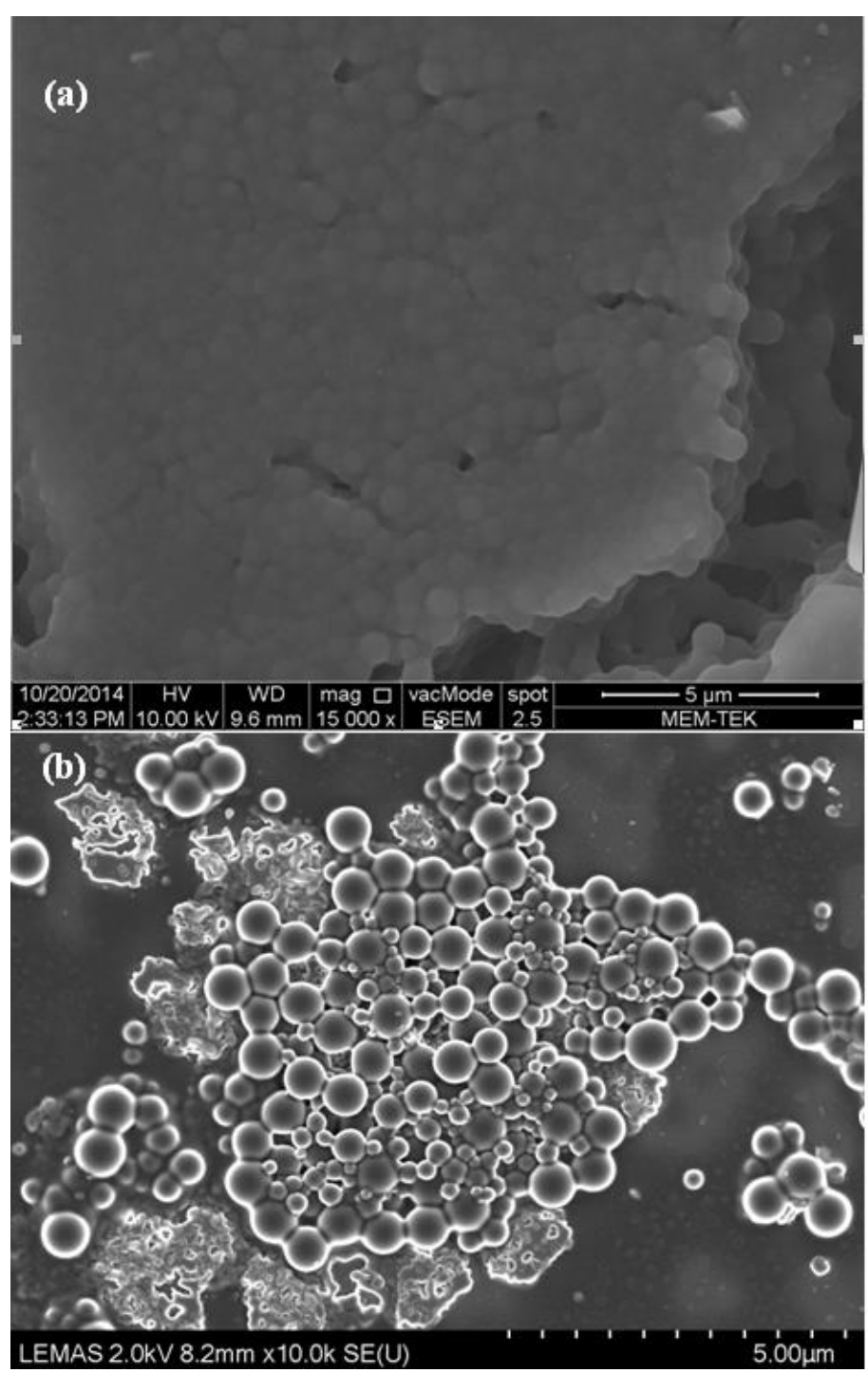

Figure 2. SEM images of pure PS and 40 wt $\%$ PS in PS/PVA composites. by FEI - Quanta FEG 250 and HITACHI, respectiveley. 


\subsection{Theoretical Considerations}

The percolation threshold, $p_{\mathrm{c}}$ for this problem is around 0.6 for so called "site percolation" on a square lattice. An example of percolation is that is the spread of water displacing oil in porous rocks, where neighboring pores are connected by small capillary channels(Sahini \& Sahimi, 1994), (Broadbent \& Hammersley, 1957).

$$
\left.p_{\infty}(p) \approx\left(p-p_{c}\right)^{\beta} \quad \text { for } p>p_{c}, \text { and } p \rightarrow p_{c}\right)
$$

In a simple cubic lattice $p_{\mathrm{c}}$ is found to be 0.31 for sitepercolation and 0.249 for bond percolation models(Stauffer, 1985). The exponent $\beta$ for a simple cubic lattice is 0.45 , for percolation model, however, $\beta$ is almost the same value as 1.0 in classical model(Stauffer, 1985).

The stages of the film formation process were modelled by the void closure and the interdiffusion models detailed information of which can be found in the studies(Ugur et al., 2011; Yargi, Gelir, Ozdogan, Nuhoglu, \& Elaissari, 2016) before and after the healing temperature, respectively.

The relation between the transmittance and the temperature during these stages is given by the following equation

$$
I(T)=S(t) \exp \left(-\frac{3 \Delta H}{k T}\right)
$$

where $S$ is a constant and $I=I_{\mathrm{tr}} /\left(I_{\mathrm{tr}}\right)_{\max }, \Delta H$ is the energy of void closure of viscous flow. One mole of material for creating the act of a jump during viscous flow and $k$ is the Boltzmann constant. The activation energies can be calculated by using the linear regression analysis as given in our previous study(Ugur et al., 2011)

\section{Results and Discussion}

The scattered light intensity, $\mathrm{I}_{\mathrm{sc}}$ versus PS volume denoted by $R(\mathrm{wt} / \mathrm{wt})$ is plotted in Fig 3a, where addition of PS into PS/PVA composite lattice drops $\mathrm{I}_{\mathrm{sc}}$, especially below $40 \mathrm{wt} \%$ PS content (see Fig 3b). This tendency of $\mathrm{I}_{\mathrm{sc}}$ can be explained by percolating PS latex in PVA matrix(Stauffer \& Aharony, 1994). This percolation can be attributed to $I_{\mathrm{sc}}$ (Arda, Kara, \& Pekcan, 2013). The below equation can be used:

$$
R=\frac{M_{P S}}{M_{P S}+M_{P V A}}
$$

where $M_{P S}$ and $M_{P V A}$ stands for the weight of PS and PVA in the matrix. If $R$ is attributed to the occupation probability, $p$, of PS in the PVA lattice, percolation threshold, $P_{c}$ becomes $R_{\mathrm{c}}$, and Eq (1) returns to Eq 16.

$$
I_{s c}(R)=\left(R-R_{c}\right)^{\beta}
$$

Eq. (16) describes the percolation model for PS distribution in PVA lattice. When $R$ approaches to $R_{c}$, the largest cluster of PS spans from one end to the other end of the PVA lattice. In Fig 4, fit of the Logarithmic plot of Eq 16 to the measured points is shown and $\beta$, was calculated as 1.01 by the slope of the straight line the critical exponent, which is quite consistent with the classical model and our previous study(Ugur, Yargi, Gunister, \& Pekcan, 2008; Ugur, Yargi, \& Pekcan, 2008).
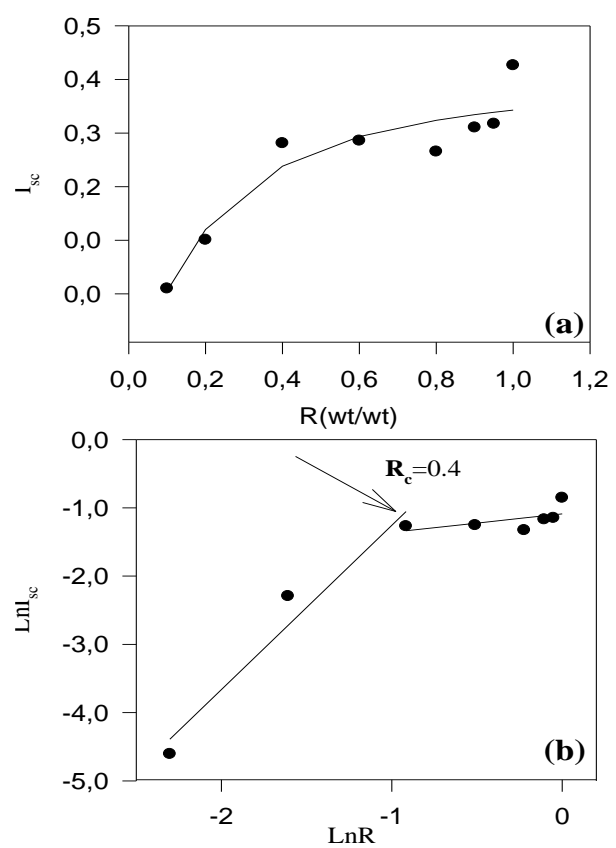

Figure 3. (a)The scattered light intensity, $I_{s c}$ versus PS volume. (b) $\operatorname{LnI}_{\mathrm{sc}}$ versus $\mathrm{LnR}(\mathrm{R}$ is the mass fraction of $R$ )

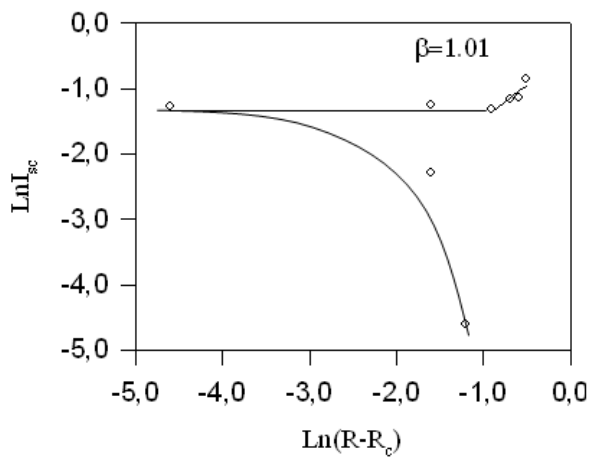

Figure 4. $\mathrm{LnI}_{\mathrm{sc}}$ versus $\mathrm{Ln}\left(\mathrm{R}-\mathrm{R}_{\mathrm{c}}\right) ; \beta$ is critical exponent

The composite films with different PS content range in 20$100 \mathrm{wt} \%$ were annealed for $10 \mathrm{~min}$ at various temperatures. The $I_{\mathrm{tr}}$ of the films, versus annealing temperature are seen in Fig. 5. Here, it is seen that $I_{\text {tr }}$ first increase and then reaches a saturation level except for the films including 95 and $100 \mathrm{wt} \%$ PS. $I_{\text {tr }}$ starts to increase at the temperature which is called onset temperature, $\mathrm{T}_{\mathrm{o}}$ which moves to the higher temperature with the increasing PS content. In other words, system needs higher temperatures to start film formation processes for higher PS volume. The void closure process is realizing above $T_{o}$ with the increase of $I_{t r}$ in which the film becomes more homogeneous as a result of decreasing porosity upon closing the voids. This increasing homogeneity of the film increases the transmitted light through the film. After the void closure stage finishes, a new stage which is called as interdiffusion process starts at the healing temperature, $T_{h}$, which increase up to a specific PS content and then show almost the same value for the rest of content values where film formation processes can be observed easily.

Observation of interdifussion process is not possible above the $90 \%$ wt PS content as seen from the Fig 5. In our previous 
study, the same behavior was observed with the addition of doping material to PS latex(Ugur, Yargi, Gunister, et al., 2008).

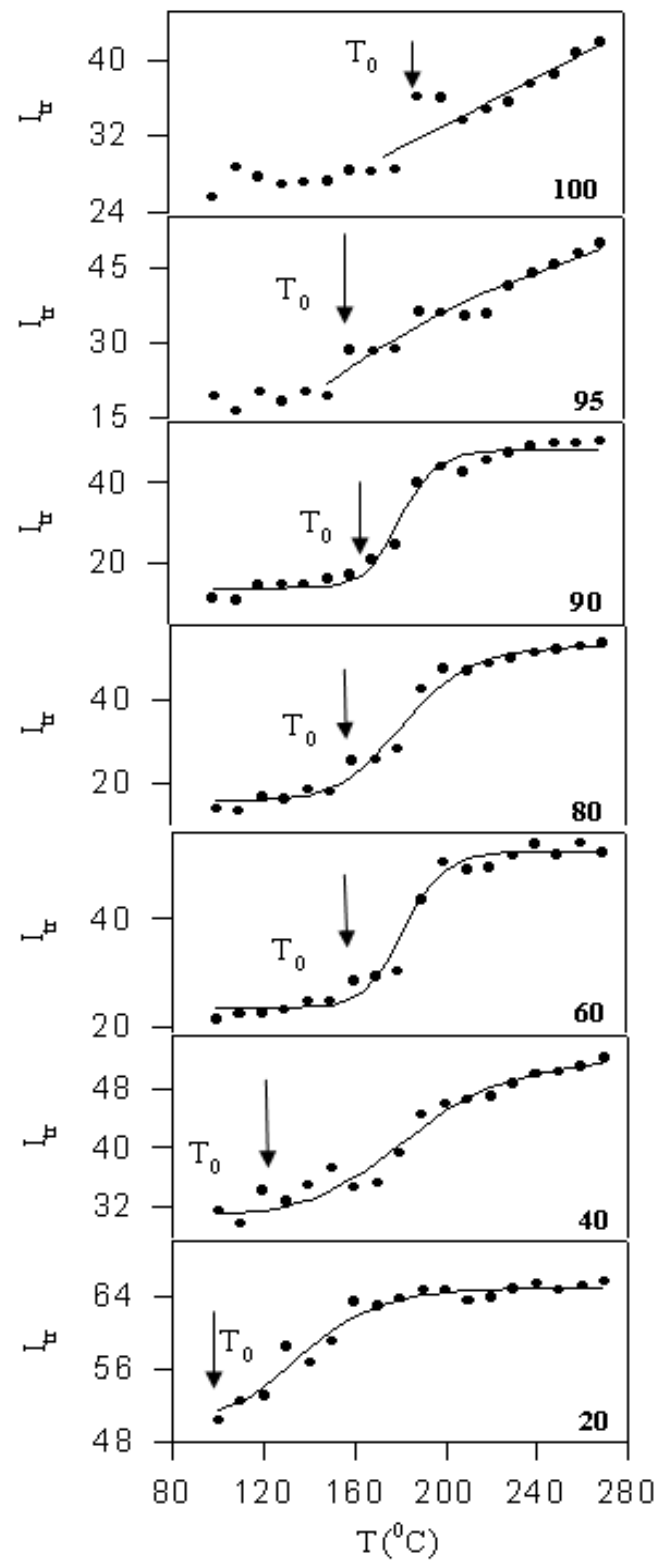

Figure 5. $\left(\mathrm{I}_{\mathrm{tr}}\right)$ change with annealing temperatures depending on. PS volume.

Logarithmic plots of $\mathrm{I}_{\mathrm{tr}}$ vs. $T^{-1}$ are presented in Fig. 6 for different PS contents. The activation energies, $\Delta E$ are calculated by the least squares fitting of the data to Eq. 14 and they were plotted versus PS content in Fig.7. Here, it is seen that while the $\Delta E$ values increase depending on the increasing PS content, $\Delta H$ values are nearly constant. This indicates that the increasing amount of the doping material in the latex film increases the required energy to accomplish the film formation. There may be one reason for not changing so much of $\Delta H$ values that aggregation does not become up to $\mathrm{T}_{\mathrm{h}}$ values in the composite films which are almost the same for all samples. In other words, viscous flow does not meet up any different potential barrier to overcome before $T_{h}$ and causes to be almost the same value of $\Delta H$. It is also seen that the $\Delta \mathrm{E}$ values are much higher than $\Delta \mathrm{H}$, because the PS particles can screen the motion of the polymer chains across the junction. In other words, interdiffusion of polymer chains needs more energy to cross over the junction surface than the jump of one mole of polymeric material during the viscous flow.

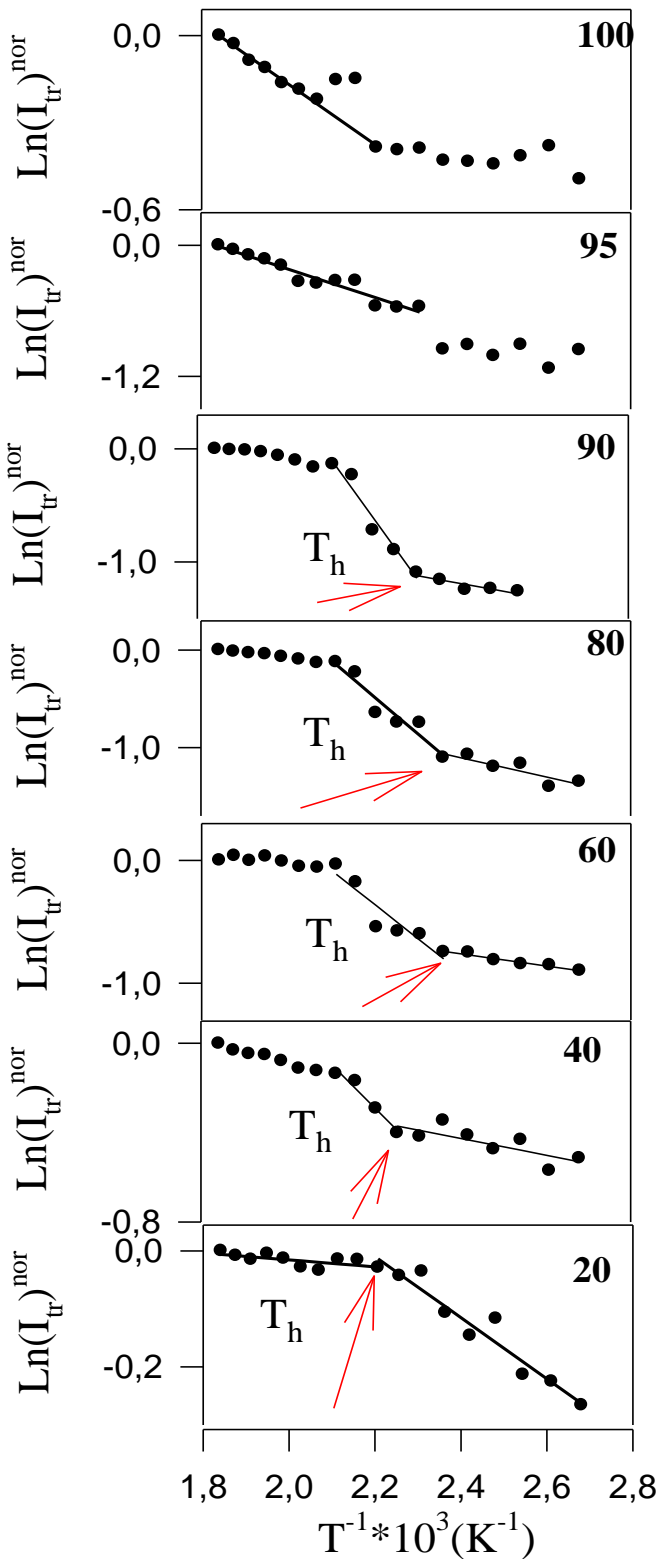

Figure 6. $\mathrm{LnI}_{\mathrm{tr}}$ versus $\mathrm{T}^{-1}$; for the 20, 40, 60, 80, 90 and $95 \% \mathrm{PS}$ volume.

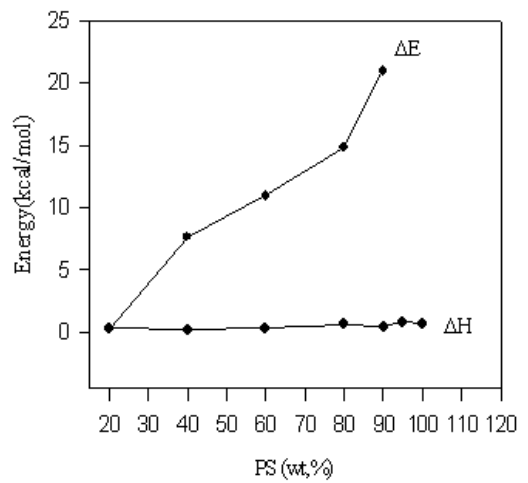

Figure 7. The void closure and interdiffusion energies $(\Delta H, \Delta E)$ are versus different PS volume.

The behavior of $\mathrm{I}_{\mathrm{tr}}$ can be explained with our other study (Fig 4)(Yargi et al., 2016) Since there is no mobility between the PS powders up to a certain temperature $\left(T_{h}\right)$, there is no change in light transmittance. However, after the glass transition 
temperature, the particles begin to move and the location of the gaps also changes. As the temperature continues to increase, the boundaries of the spheres that begin to fuse begin to disappear and the voids tend to fill. This situation causes the light transmittance to increase up to the fusion temperature. After a certain temperature, the particles cannot move any more either. Because the voids are filled, or because there is a clustering situation depending on the system, it causes the formation of porous structures and a decrease in light transmission. Here, it is not possible to observe the film formation process for composite lattice after the 90 PS wt\% value. In other words, for samples with higher PS amount, PT technique is not suitable for to see the deatiled $\mathrm{I}_{\text {tr }}$ change, because the light is blocked by the PS particles and does not allow the transition of itself. In conclusion, it can only be worked below PS 90 wt.\%. The morphological changes were found to be consistent with the photon transmission technique results. As seen from Fig. 2a, while pure PS particles has less voids between the spherical particles than the films with $40 \mathrm{wt} \%$ PS content as in Fig. 2 b. Aggregation which occurs with the addition of PS to the composite films causes the transmitted light intensity to decrease as we have already discussed before.

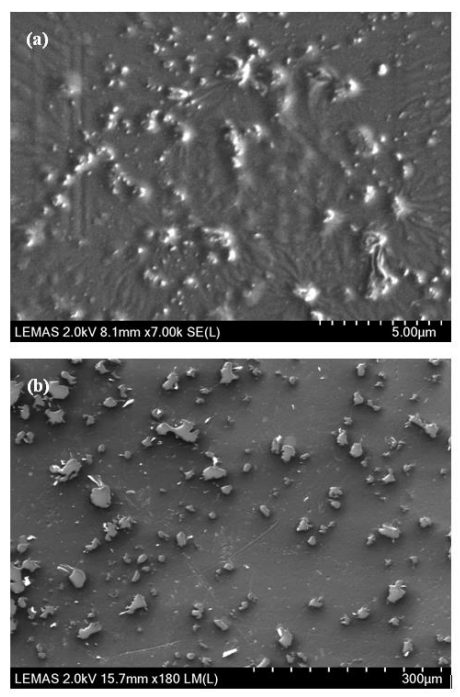

Figure 8. SEM pictures of PVA for the thickness (a) $45 \mathrm{~mm}$, and (b) $170 \mathrm{~mm}$ at $90{ }^{\circ} \mathrm{C}$.

\section{Conclusions and Recommendations}

This work presents a film formation from PS/PVA latexes in terms of mechanical and optical properties. Below $90 \mathrm{wt} \%$ PS content, void closure and interdiffusion regions were observed. While, above $90 \mathrm{wt} \%$ PS interdiffusion processes was only seen. On the other hand, $\mathrm{I}_{\text {tr }}$ passing through the films was observed to the PS prescence in the composite matrix. Activation energies energies were also presented. While $\Delta \mathrm{E}$ increased with PS content, only slightly change was seen in $\Delta \mathrm{H}$ values depending on doping material.

\section{References}

Arda, E., Kara, S., \& Pekcan, O. (2013). Phase Transitions, 86(10), 1017-1032. doi:10.1080/01411594.2012.751535

Broadbent, S. R., \& Hammersley, J. M. (1957). Mathematical Proceedings of the Cambridge Philosophical Society, 53(3), 629-641. doi:10.1017/S0305004100032680
Chan, K. S., Senin, H. B., \& Naimah, I. (2009). Nanoscience and Nanotechnology, 1136, 366-369. Retrieved from <Go to ISI>://WOS:000268921300072

Chan, L. W., Hao, J. S., \& Heng, P. W. S. (1999). Chemical \& Pharmaceutical Bulletin, 47(10), 1412-1416. Retrieved from <Go to ISI > ://WOS:000083158000011

Chen, W., Tao, X. M., Xue, P., \& Cheng, X. Y. (2005). Applied Surface Science, 252(5), 1404-1409. doi:10.1016/j.apsusc.2005.02.138

Fukumori, T., \& Nakaoki, T. (2013). Open Journal of Organic Polymer Materials, $\quad$ 03, 110-116. doi:10.4236/ojopm.2013.34018

Hallensleben, M. L. (2000).. Ullmann's Encyclopedia of Industrial Chemistry. doi:10.1002/14356007.a21_743

Jiang, S., Liu, S., \& Feng, W. H. (2011). Journal of the Mechanical Behavior of Biomedical Materials, 4(7), 12281233. doi:10.1016/j.jmbbm.2011.04.005

Kelly, C. M., DeMerlis, C. C., Schoneker, D. R., \& Borzelleca, J. F. (2003). Food and Chemical Toxicology, 41(5), 719-727. doi:10.1016/S0278-6915(03)00003-6

Mackenzie, J. K., \& Shuttleworth, R. (1949). Proceedings of the Physical Society. Section B, 62(12), 833-852. doi:10.1088/0370-1301/62/12/310

Paiva, M. C., Zhou, B., Fernando, K. A. S., Lin, Y., Kennedy, J. M., \& Sun, Y. P. (2004). Carbon, 42(14), 2849-2854. doi:10.1016/j.carbon.2004.06.031

Pekcan, O. (1997). Trends in Polymer Science, 5(6), 177-180. Retrieved from <Go to ISI>://WOS:A1997XG73500002

Provder T., W. M. A. a. U. M. W. (1996). (Vol. 648). Washington DC.: American Chemical Society.

Ray, S. S., \& Okamoto, M. (2003). Progress in Polymer Science, 28(11), 1539-1641. doi:10.1016/j.progpolymsci.2003.08.002

Sahini, M., \& Sahimi, M. (1994). london: Taylor and Francis.

Sperry, P. R., Snyder, B. S., Odowd, M. L., \& Lesko, P. M. (1994). Langmuir, 10(8), 2619-2628. doi:DOI 10.1021/la00020a021

Stauffer, D. (1985). Introduction to Percolation Theory. London: Taylor and Francis.

Stauffer, D., \& Aharony, A. (1994). Introduction To Percolation Theory. London: Taylor\&Francis.

Ugur, S., Yargi, O., Durmaz, Y. Y., Karagoz, B., Bicak, N., Yagci, Y., \& Pekcan, O. (2011). Polymer Composites, 32(6), 869-881. doi:10.1002/pc.21094

Ugur, S., Yargi, O., Gunister, E., \& Pekcan, O. (2008). Applied Clay Science, $\quad 42(1-2), \quad 39-49$. doi:10.1016/j.clay.2008.02.009

Ugur, S., Yargi, O., \& Pekcan, O. (2008). Polymer Composites, 29(2), 179-186. doi:10.1002/pc.20378

Xu, Y. X., Hong, W. J., Bai, H., Li, C., \& Shi, G. Q. (2009). Carbon, 47(15), doi:10.1016/j.carbon.2009.08.022

Yang, D. Z., Li, Y. N., \& Nie, J. (2007). Carbohydrate Polymers, 69(3), 538-543. doi:10.1016/j.carbpol.2007.01.008

Yargi, O., Gelir, A., Ozdogan, M., Nuhoglu, C., \& Elaissari, A. (2016). Journal of Applied Polymer Science, 133(15). doi:10.1002/app.43289

Yoo, J. N., Sperling, L. H., Glinka, C. J., \& Klein, A. (1991). Macromolecules, 24(10), 2868-2876. doi:DOI 10.1021/ma00010a036

Zhang, J., Wang, J. F., Lin, T., Wang, C. H., Ghorbani, K., Fang, J., \& Wang, X. G. (2014). Chemical Engineering Journal, 237, 462-468. doi:10.1016/j.cej.2013.10.055. 